\title{
Risk Analysis and Control Measure of Gas Power Generation Enterprise
}

\author{
Wang Qi-quan, Yan Xiang-dou \\ Department of Safety Engineering, China University of Labor Relations, Beijing, China
}

Email address:

wqq_100@163.com (Wang Qi-quan)

\section{To cite this article:}

Wang Qi-quan, Yan Xiang-dou. Risk Analysis and Control Measure of Gas Power Generation Enterprise. International Journal of Science and Qualitative Analysis. Vol. 3, No. 2, 2017, pp. 15-22. doi: 10.11648/j.ijsqa.20170302.12

Received: September 21, 2017; Accepted: October 23, 2017; Published: November 10, 2017

\begin{abstract}
In order to study the accident risk of gas power plant, and through the nearly ten years of statistical analysis of gas power plant accident, failure to get the presence of risk factors of gas power plant. Use explanation structure model, structural analysis of the identified risks, through expert for each system within the relationship between the risk factors of comparison, identify the gas leakage at the risk and risk factors, step by step under the top building structural relationships. Secondly, using fuzzy analytic hierarchy process to evaluate the risk factors quantitatively, the gas system is the main risk. Finally, the risk of the gas leakage accident is evaluated. Based on the case of the Jing Feng gas power plant, the safety countermeasures are put forward to provide guidance for gas generation enterprises.
\end{abstract}

Keywords: Gas Power Station, Accident Risk, ISM, FAHP, QRA

\section{Introduction}

Gas power generation technology is conducive to the sustainable development of national economy, to effectively improve the current situation of power generation enterprise high pollution, and gas power lower cost compared to traditional power are normally more efficient power output. Although gas power generation technology is an advanced power generation technology, but it also exists certain risk factors, as a domestic energy companies of gas power plant and conventional thermal power plant accident rate, coal-fired power plant capacity in every 100 million KWH 0.20 .4 times the fault happens, every 100 million kilowatt hours of electricity and gas turbine power plant fault occurs 1-2 times visible gas about 5 times higher failure rate than coal-fired power generation. It is necessary to identify and evaluate the risks of gas generation, and propose effective safety management and technical countermeasures.

Risk of accidents in gas power plant by scholars at home and abroad research made some achievements, foreign scholars use the concept of hierarchical analysis divide the accident risk of gas power plant hierarchy [1], the method in the study of the risk of power plants have a vital role, using the fuzzy mathematics and analytic hierarchy process (AHP) is a bit he will reduce risk factors of subjective judgment factors, improve the accuracy of the analysis of risk factors [2]. Using $\mathrm{VaR}$ and the CVaR method of risk measurement based on this foundation, the risk control of the power plant is measured and analyzed [3-4]. The current domestic gas production industry started relatively late, the related risk analysis and evaluation method of technology is mainly in the relatively mature power risk analysis method. Risk and risk factors in power plant accidents are identified and analyzed by [5]. On the basis of risk analysis methods in advance of each risk factor for dangerous hierarchies, formed the major risk factors of the enterprise and its control list, so that the enterprise risk control [6]. Based on the method of accident tree analysis, the research on the risk factors in the safety production process of Harbin electric power company was studied in [7]. Through reference to the study of the theory of the risk management, hierarchical holographic model of building enterprise risk model and classical explanation structure model to find the relationship between the different risk factors. To optimize the control measures of risk by means of risk measurement, the paper puts forward the effective and feasible management measures [8]. Combined with the experience of production management, the multi-level fuzzy evaluation method was introduced to identify and evaluate the risk factors of the power generation enterprise. In this paper, the accident risk of gas power plant were analyzed, and the annual number of 
accident statistic analysis is based on the power plant and power plant actual risk factors existing in the operation process of the concrete, the accident risk model is put forward to analyze the power plant overall risk condition and the accident risk, and high risk of harmful consequences. The countermeasures and Suggestions for the safety production management of the power plant are put forward, and the reference for the safe production of gas power plant is provided.

\section{Analysis of Accident Risk of Gas Generator}

\subsection{Gas Generation Accident Data Statistics}

The gas generation equipment is made in the form of high temperature and high pressure, so the damage to the equipment is greater. Again because of gas power generation in China is mainly used as load, frequent stops and use, increased gas equipment damage, easy to cause accident or equipment failure. Through to the Guang Dong-Hui Zhou M107F type gas power plant (2007-2012) analyzed the operation of the gas turbine equipment fault below, gas power generation equipment accident frequency is higher when the main reason for the quality defect and operational problems.

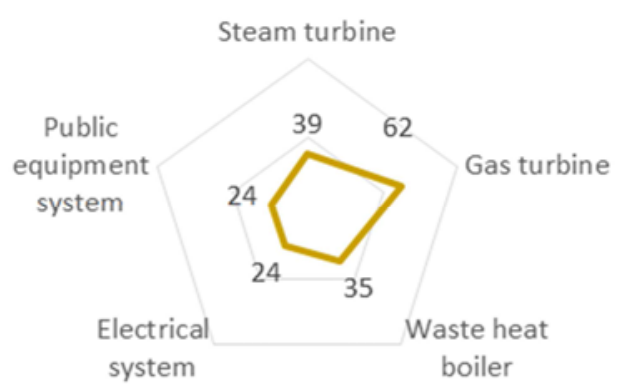

Figure 1. Accident statistics of gas generating equipmen.

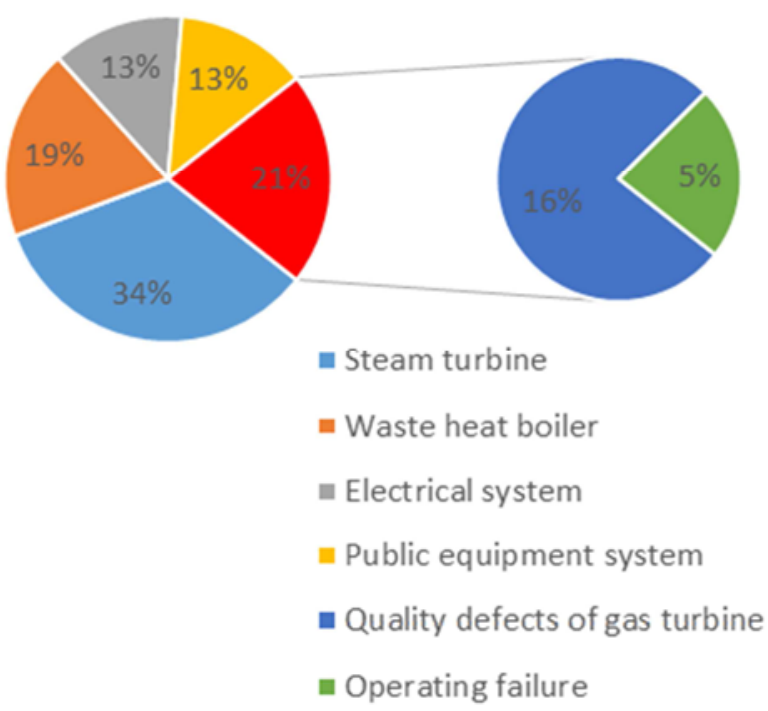

Figure 2. Gas turbine accident statistics.
The gas accident statistics in China in recent years are shown in figure 3. Although natural gas is a safer fuel, it is a major danger that exceeds the limits of natural gas reserves. In the process of safe production, we should be vigilant.

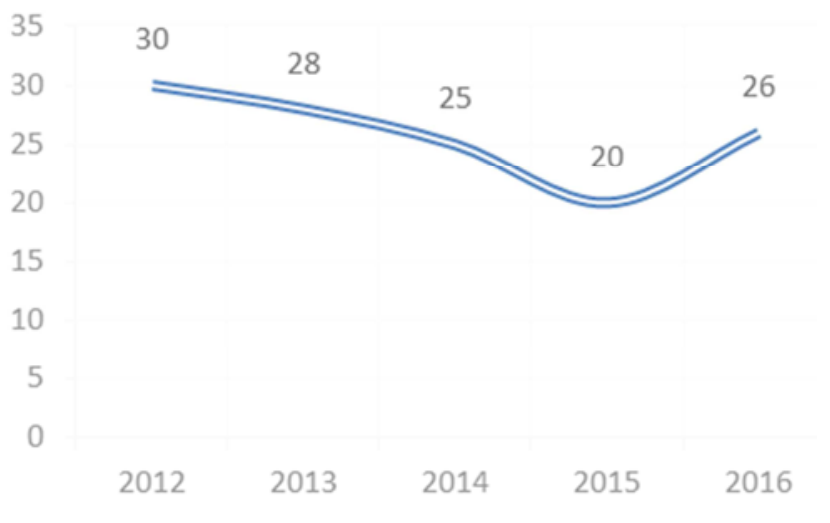

Figure 3. Accident statistics of gas supply.

\subsection{JSA Security Analysis}

Through JSA job safety analysis to the risk of gas power generation enterprises had the further understanding, in order to more clearly show that the gas power plant is the main risk, in the form of a process flow diagram, as shown in figure 4.

\subsection{Accident Risk Identification}

Through the front for risk analysis of gas power generation enterprise risk accident statistics, we can find that the gas power plant combustion gas turbines and steam turbines is accident of equipment the damage and serious consequences. Waste heat boilers, electrical systems, environmental factors, human factors and management factors are important risk factors affecting gas power plants. So as a risk factor for gas power plant for the first layer of risk, to the artificial factor, gas turbine, steam turbine, waste heat boiler, gas system, electrical system, environmental factors, management risk factors for the second floor, after analysis of each risk. In this paper, a multilevel multidimensional risk model can be divided into a comprehensive analysis of the main risks and risks of gas power plants. Draw the risk model diagram as shown in figure 5.

\section{Construction of the Risk Model of Gas-Fired Power Plant}

\subsection{Model Selection}

Core equipment in domestic gas generating equipment is imported more, general accessory equipment for the domestic product, compared with foreign gas power plant of domestic gas equipment brand variety, the overall lack of systemic. And gas power plant is no longer just a few aspects of risk, but a complex system, analysis of the system within each subsystem and the relationship between the number of elements is difficult. An explanation of the structure model can be used to 
transform a large number of variables, complex structures, and structures that are not clear. Therefore, the analysis of complex system by explanation structure model can be used to find the relationship of the system, and the structure model of a staircase model is summarized. By establishing a model, we can help us to understand the complex relationship structure, and make the structure relation intuitive. Combined with fuzzy analytic hierarchy process (AHP) based on as far as possible to reduce the influence of subjective factors, the fuzzy analytic hierarchy process (AHP) is put forward to analyze the existing power plant specific risks, and the major risks for quantitative risk analysis. Power plant based on the actual case of the risk of power plant specific control measures are put forward, using computer software to build the risk model, analysis the accident process is the focus of the present study.

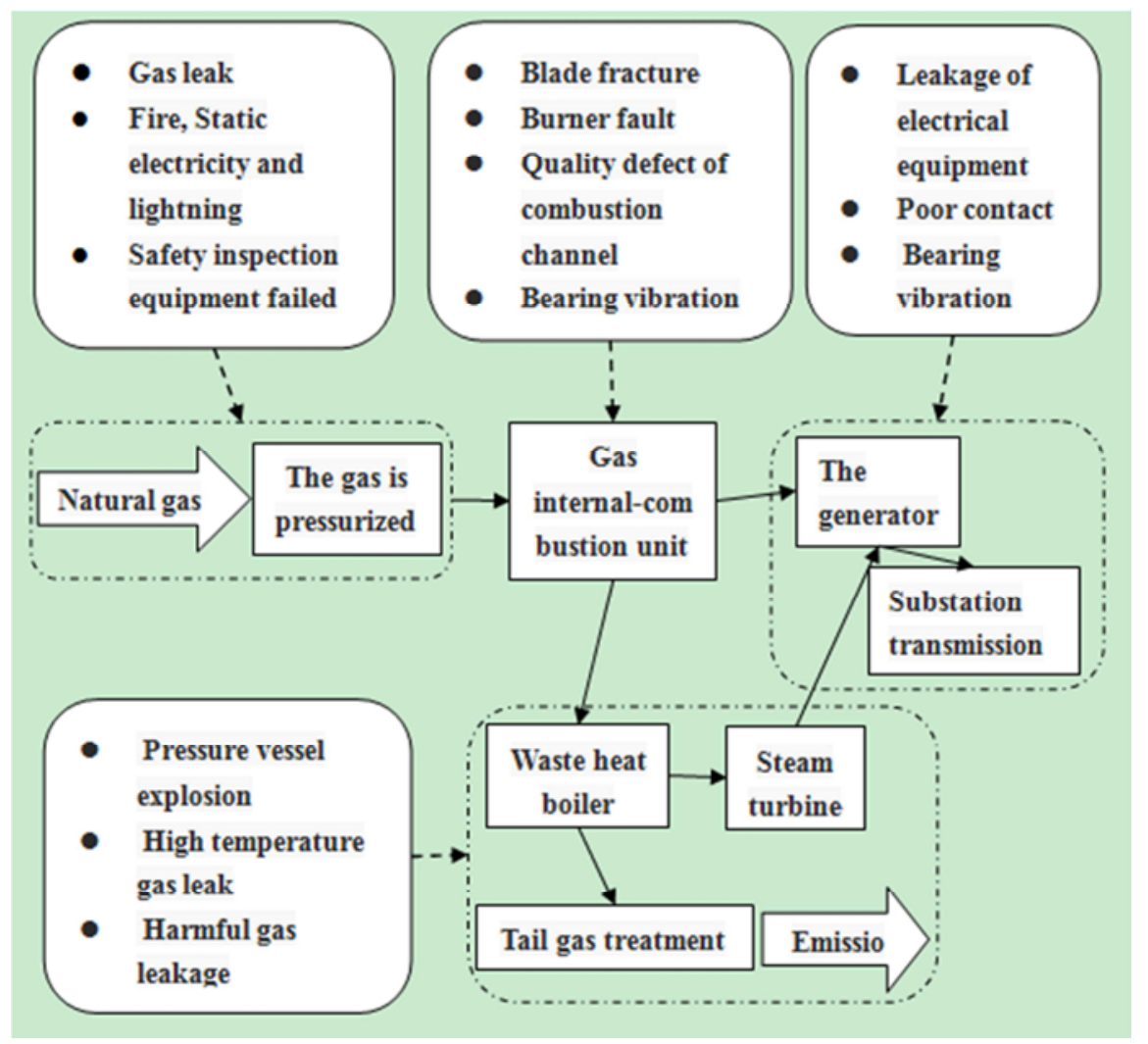

Figure 4. Process flow.

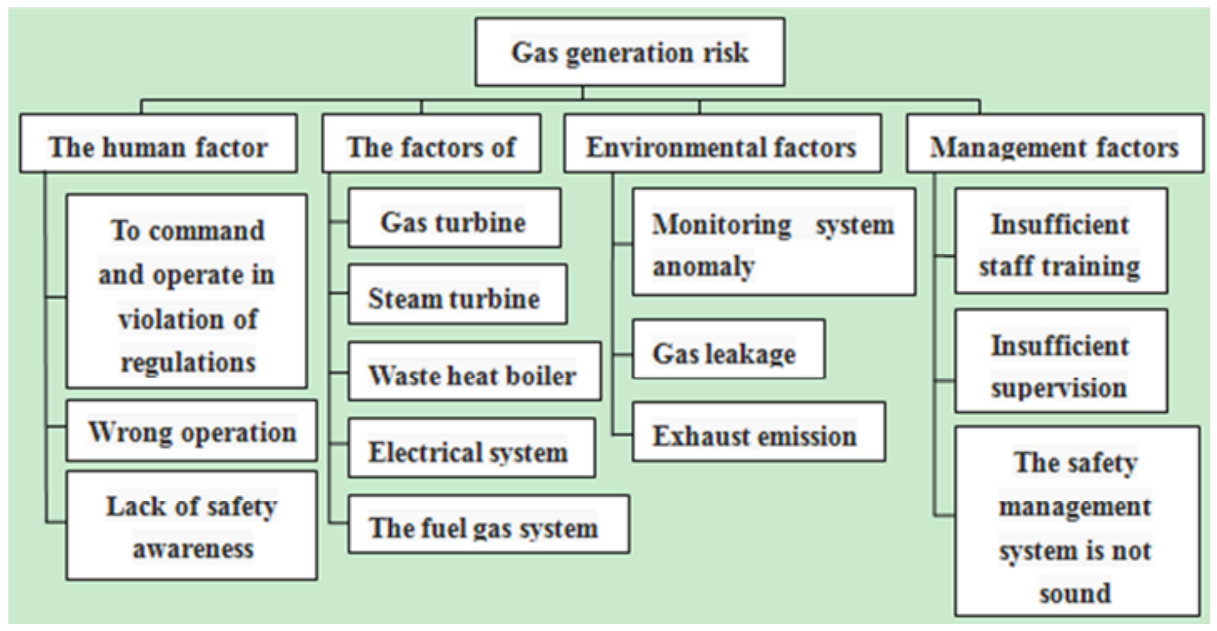

Figure 5. Gas generation risk factors.

\subsection{Model Building}

\subsubsection{Build the Explain Structure Model}

Will issue the relevant factors related to logic analysis consists of 0,1 , adjacency matrix, then the logic operations of the problem of matrix, based on the analysis of various elements of the reachable matrix accessible point divides the factors determine the hierarchical structure, on the basis of 
hierarchical diagram.

Adjacency Matrix (Adjacency Matrix): it is said the adjacent relation between each factor Matrix. Let's say that $\mathrm{G}$ $=<\mathrm{V}, \mathrm{E}>$ is A simple matrix relationship, and he has n nodes $\mathrm{V}=\left(\mathrm{v}_{1}, \mathrm{v}_{2}, \ldots \mathrm{v}_{\mathrm{i}}\right)$, and the $\mathrm{n}$-Th order matrix $\mathrm{A}(\mathrm{G})=\left(\mathrm{a}_{\mathrm{ij}}\right)$ is the adjacency matrix for $\mathrm{G}$.

The matrix is the degree to which the relationship links in the matrix are analyzed. Let's say that $\mathrm{G}=<\mathrm{V}, \mathrm{E}>$ is a simple matrix relationship, and he has $n$ nodes $\mathrm{V}=\left(\mathrm{v}_{1}, \mathrm{v}_{2}, \ldots \mathrm{v}_{\mathrm{i}}\right)$, and the $\mathrm{n}$ order square $\mathrm{P}=\left(\mathrm{P}_{\mathrm{ij}}\right)$ is the adjacency matrix for $\mathrm{G}$.

According to the results of gas power generation risk identification, risk of gas power generation enterprises structure of hierarchical analysis, through expert survey mark can be up to the vector relation between factors and establish the relation model, in order to establish the adjacency matrix. MATLAB software is used to calculate the matrix. Turn the two matrices into two sets of accessible and preset. By the formula

$$
\mathrm{R}(\mathrm{ri})=\mathrm{R}\left(\mathrm{r}_{\mathrm{i}}\right) \cap \mathrm{A}\left(\mathrm{r}_{\mathrm{i}}\right)
$$

Risks can be assessed.

\subsubsection{Fuzzy Level Analysis Model}

In this paper, the fuzzy layer analysis model is constructed, which is based on the expert's questionnaire, which compares the risk factors. The weight matrix was weighted by MATLAB software, and the weight consistency was tested.

Again according to expert questionnaire to determine the accident risk of the enterprise level to hazard possibility and consequences of fuzzy safety evaluation matrix and accident risk weighting matrix multiply by gas safety accident risk evaluation indicators, its expression:

$$
H_{i}=w_{i} \times R_{i}
$$

$w_{i}$ Weight matrices

$R_{i}$ Safety rating matrix

(2) Parameter setting

Before the operation should choose the appropriate map scale, and the gas power generation enterprise basic data are serious, dangerous chemicals stock, distribution parameters of pipeline, meteorological condition and the distribution of the surrounding buildings. The flow of computing is approximately as shown in figure 7 .

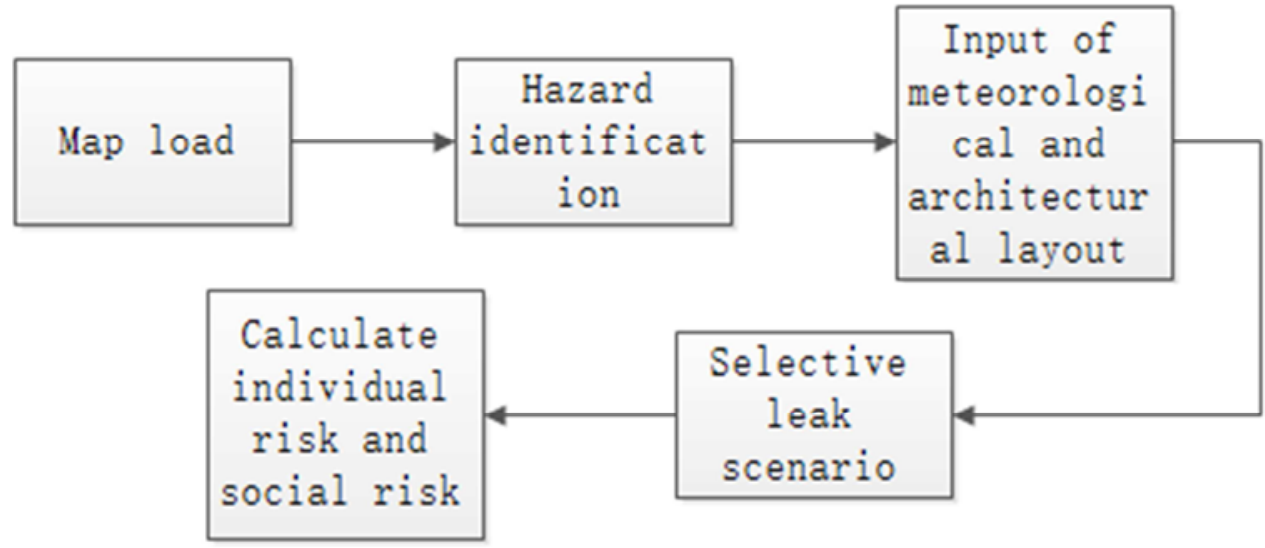

Figure 7. Calculation flow chart.

\subsubsection{Quantitative Risk Analysis Model}

(1) Google Earth map location

Use Google Earth to gas power generation enterprise locates, clear map scale, based on the actual investigation of the actual measurement data input system, clear the scope of the factory good enterprise. This is an important step in QRA's analysis, which is detailed and accurate to ensure the basis of the subsequent analysis of personal risks and social risksin the gas power plant area.

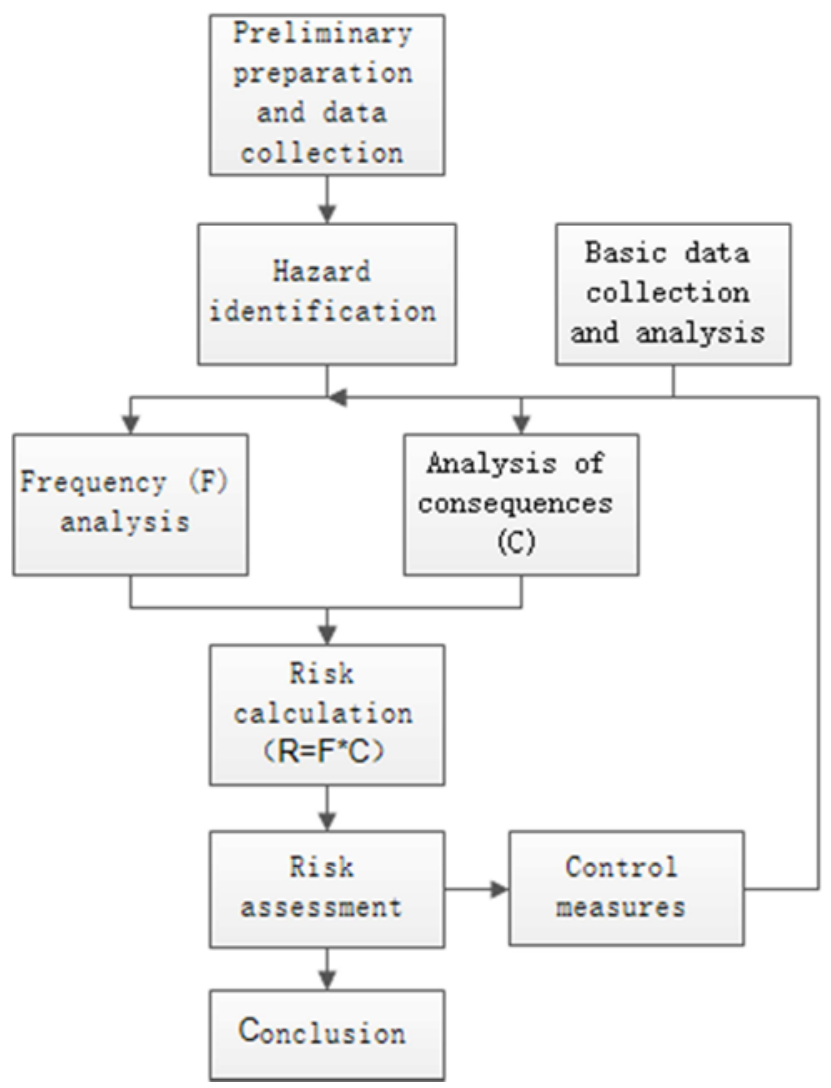

Figure 6. $Q R A$ analysis process. 
(3) Calculated risk

The use of CASST QRA according to the different leakage model, calculate the corresponding individual risk and social risk, and according to the analysis of the calculation results of different leakage model evaluation.

\section{Instance Verification Analysis}

\subsection{Instance Profiles}

Jing-Feng gas power generation co., LTD., Beijing currently employees 451 people, plant area of $245000 \mathrm{~m} 2$, there are a M701F level power generation equipment, M701 level power equipment produce about 1.7 billion KWH. The Beijing Jing-Feng gas power plant, which is verified by the case, is established in the western road of Yungang, the capital, and the business circle of the east. 701 in the west; Located in the center of the Fengtai district of the southern Fengtai district, the area is $27 \mathrm{~km}$ from the center of Beijing, $4 \mathrm{~km}$ from the Beijing-stone highway, and covers an area of 245, 000 square meters.

\subsection{The Example Analysis}

(1) Build the explain structure model

Level 1: L1 $=\{7\}$ (gas leak)

Level 2: L2 $=\{10,11,47\}$ (gas turbine gas pressure equipment damaged, gas turbine gas equipment sealed, detecting system abnormality)
Layer 3: L3 $=\{26\}$ (unit protection system failure)

Level 4: L4 $=\{6,51,53\}$ (employee safety awareness, inadequate employee training, and inadequate safety management)

Diagram of the relationship between risk factors, is shown in figure 8.

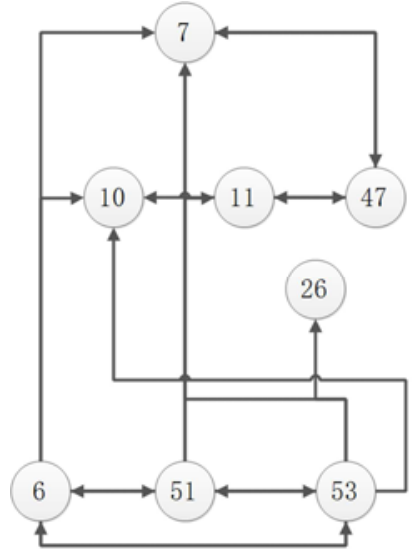

Figure 8. Gas generation enterprise risk relationship diagram.

(2) Fuzzy level analysis model

The weight of the system is calculated by MATLAB programming.

Table 1. Gas plant systems.

\begin{tabular}{lllllllll}
\hline No. & $\mathbf{1}$ & $\mathbf{2}$ & $\mathbf{3}$ & $\mathbf{5}$ & $\mathbf{6}$ & $\mathbf{7}$ & $\mathbf{8}$ & $\mathbf{9}$ \\
\hline factors & Gas turbine & Steam turbine & Waste heat boiler & $\begin{array}{l}\text { The power } \\
\text { system }\end{array}$ & Human factors & $\begin{array}{l}\text { Environmental } \\
\text { factors }\end{array}$ & $\begin{array}{l}\text { Management } \\
\text { factors }\end{array}$ & $\begin{array}{l}\text { The power } \\
\text { system }\end{array}$ \\
\hline
\end{tabular}

The maximum Characteristic root of the matrix $S$ is calculated by $\lambda_{\max }=8.9583$, the conformance test indicator:

$$
C I=\frac{\lambda_{\max }-n}{n-1}=\frac{8.9583-8}{8-1}=0.1369
$$

Average random conformance indicators.

$R I=1.41$. Random consistency ratio:

$$
C R=\frac{C I}{R I}=\frac{0.1369}{1.41}=0.0971<0.10
$$

According to the result analysis $\mathrm{CR}<0.01$, the weight is reasonable.

The weight vector between the main systems of the power plant:

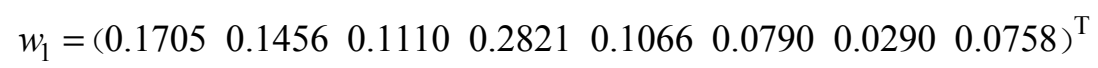

As we can see by the weight value in gas power plant gas turbine, steam turbine, waste heat boiler, gas system, power system, human factors, environmental factors, management factors gas system the biggest risk in the system. In this case, the factors in each system are weighted. Using the combustion system as an example, by calculating the weight vector of the gas system,

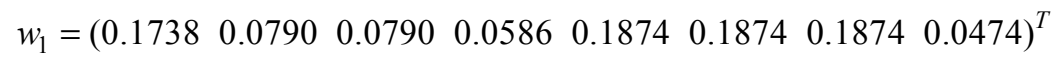

Again by the weight of gas turbine and gas turbine expert evaluation matrix, the gas turbine weight vector multiplied by the 
fuzzy evaluation matrix of gas turbine gas turbine secondary index evaluation vector:

$$
\left.H_{1}=w_{1} \bullet R_{1}=\left[\begin{array}{c}
0.1738 \\
0.0790 \\
0.0790 \\
0.0586 \\
0.1874 \\
0.1874 \\
0.1874 \\
0.0474
\end{array}\right]^{T} \cdot \bullet \begin{array}{lllll}
0.2 & 0.4 & 0.2 & 0.2 & 0 \\
0.2 & 0.5 & 0 & 0.3 & 0 \\
0.2 & 0.3 & 0.5 & 0 & 0 \\
0.1 & 0.3 & 0.2 & 0.3 & 0.1 \\
0.3 & 0.4 & 0.1 & 0.2 & 0 \\
0.3 & 0.3 & 0.1 & 0.3 & 0 \\
0.1 & 0.4 & 0.3 & 0.2 & 0 \\
0 & 0.5 & 0.2 & 0.2 & 0.1
\end{array}\right]=\left\{\begin{array}{lllll}
0.2034 & 0.39014 & 0.18916 & 0.2167 & 0.0106\}
\end{array}\right.
$$

For fuel gas system, based on the principles of maximum membership degree gas system of the degree of risk is bigger, therefore needs the enterprise to improve the employees' safety consciousness, sealed, and the influence of abnormal detection system is the largest. By comparing the risk degree of the other system, the gas system was found to be the most risky, so it was analyzed quantitatively.

Jing-Feng gas power generation, which is a gas station in the central government of the government of the main gas pipeline in Shanxi Province, was introduced to the gas station after the filtration of pressure. Statistical data in recent years, the region is mainly the northerly winds, in recent years, the average wind speed $2.4 \mathrm{~m} / \mathrm{s}$, annual average temperature $12^{\circ} \mathrm{C}$. The gas station has a pipeline to deliver high-pressure gas to the main engine room of the gas turbine (DN200 P = 6.4 MPa)

(1) The consequence of the accident

The gas pressurized station accident simulates the disaster mode by means of the complete rupture of the pipe, the leakage of the big hole and the accident in the middle hole. The result of the accident is that the radius of death is $55 \mathrm{~m}$, and the result of the leak is shown in red. Its domino effect radius is a circular region of $53 \mathrm{~m}$.

(2) Personal risk analysis

The computed value of the individual risk probability is shown in figure 10, which is shown by the results:

$1 * 10^{-5}$ personal risk contour is not out of the factory, $1 *$ $10^{-7}$ personal risk contour has affected the east north road work, while $1 * 10^{-8}$ is beyond the west plant area of $82 \mathrm{~m}$, the north campus $51 \mathrm{~m}$, spread to the west side 701 and residential building and the factory of hydrogen station in the north. But it did not affect the area of employee living in the factory area.

(3) Social risk analysis

As shown in figure 11 , the cumulative probability of 10 deaths is $1 * 10^{-8}$, within acceptable limits.

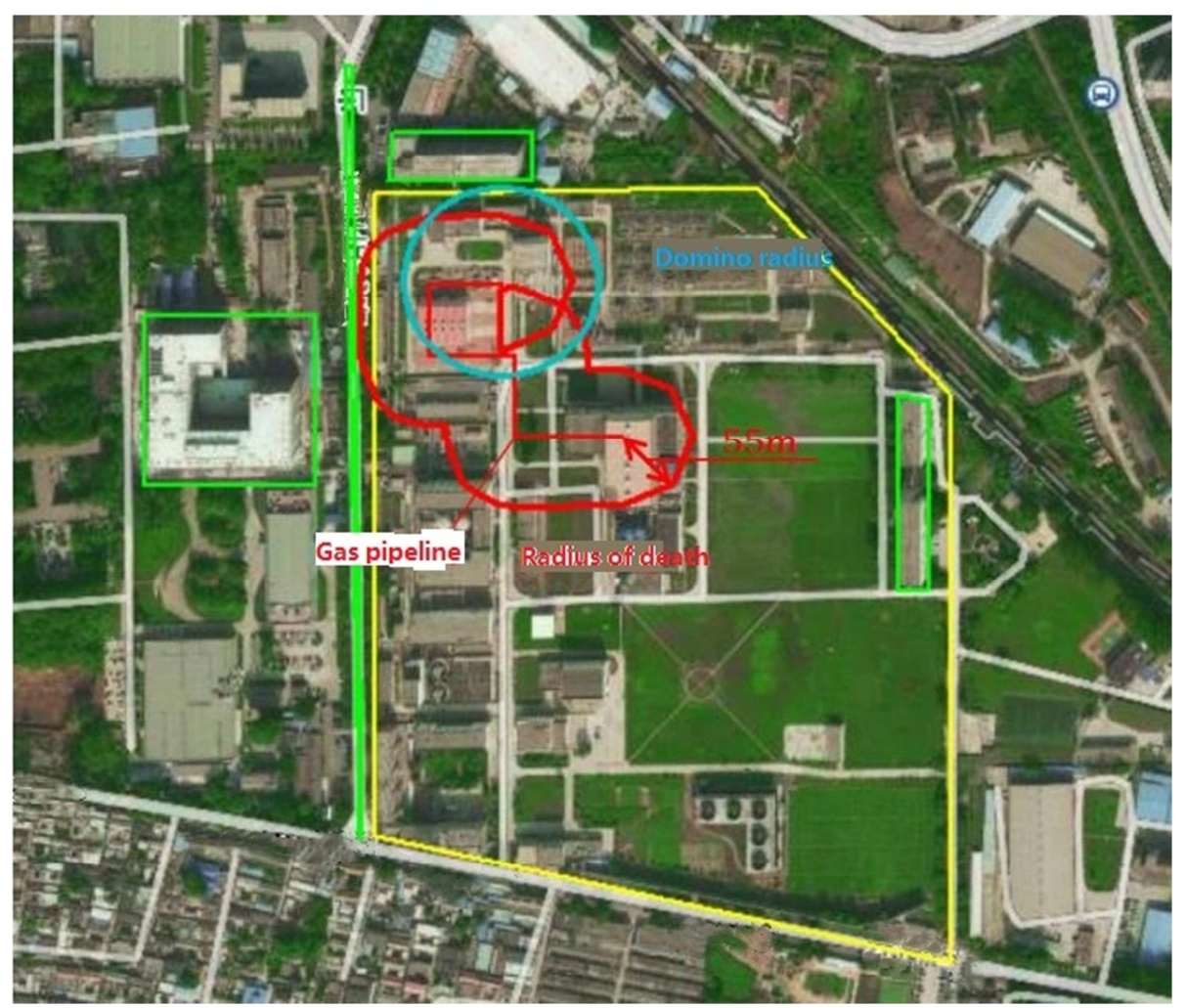

Figure 9. Accident consequences diagram. 


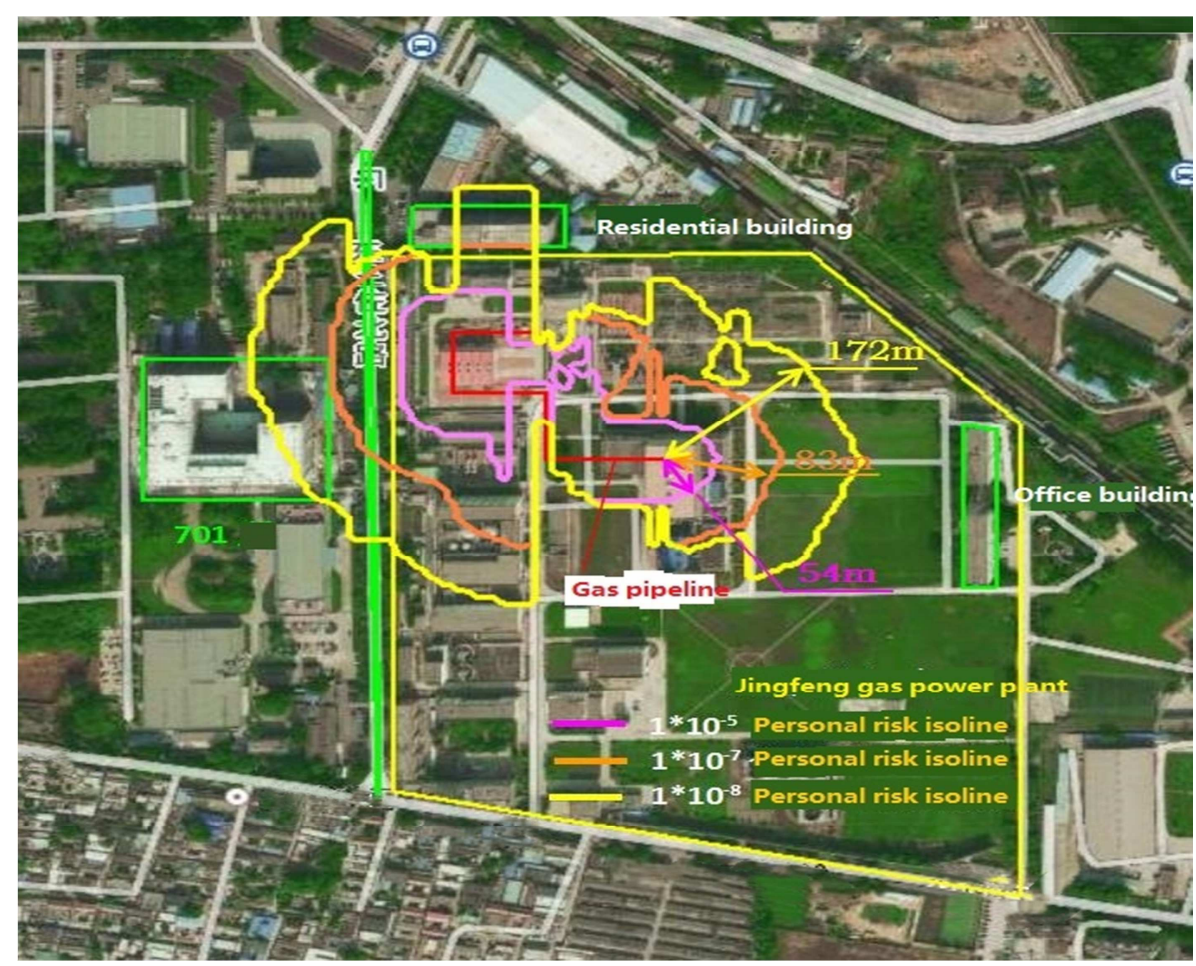

Figure 10. The contour of the individual risk.

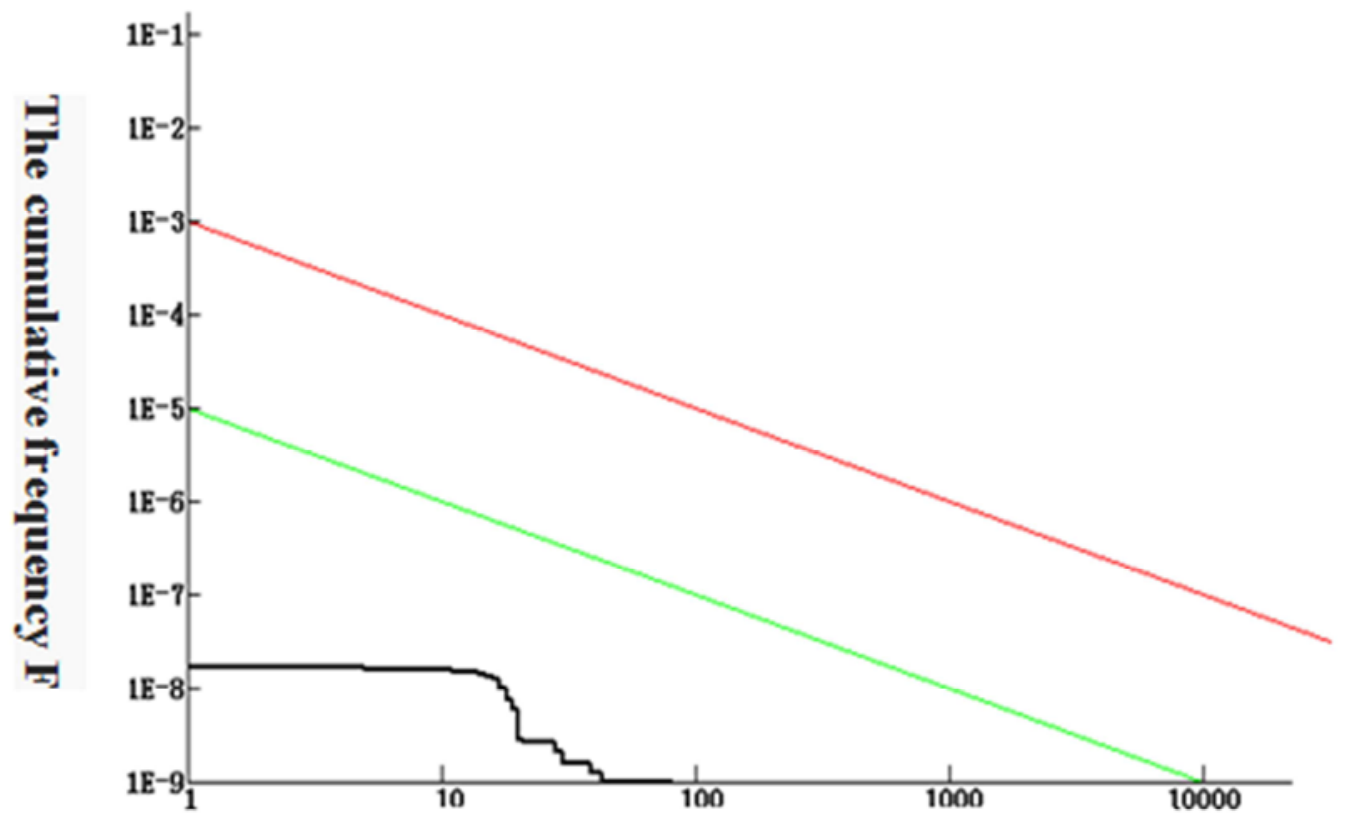

The number of possible deaths

Figure 11. Social risk curve.

\subsection{Suggestion Game}

1) Human factors

According to ISM and JSA analysis is wrong operation of each system can achieve the underlying factors, so we need to strengthen to the staff management from the aspects of safety management system, perfect management system to carry out the operation ticket, organize employee daily learning relevant safety knowledge, improve the level of security from the consciousness of the employees. People, according to the laws of the sea due to the system in the security problem is the basic cause of the accident, so improve the understanding of employee's personal safety and safety management is particularly important.

2) The factors of 
Factors such as the safety of machine equipment and equipment are the direct factors. Working in the factory according to the design requirements of the state to design, assemble, run, as far as possible eliminate the controllable factors brought about by accident, this requires the enterprise need in equipment installation, operation, maintenance and other aspects to carry on the control, as far as possible do intrinsically safe, ensure that the equipment under what condition can ensure equipment safety state.

3) work environment

Environmental factors are an unavoidable influence on corporate security, and can directly affect the safety of gas plants. Employees operating environment temperature, intensity of illumination, the concentration of harmful gases, operating space, high protection facilities, the factory floor clean and risk zoning shall conform to the safety of man-machine engineering and the relevant provisions of the state standard. At the entrance of the factory, the hazard factors and the warning signs of the processing method should be posted.

4) production safety management

Management is an important part of the process, and there are no effective management mechanisms that are prone to all kinds of safety accidents. For management, it is need to management from the system, according to the national requirements specify the relevant system, personnel holding special operation certificates to participate in special operations, improve special contingency plans formulated by some content not improve the PPE equipment management regulations. From the education on management, making itself has the high quality employees, no chances to take the risk operation is the enterprise make its own there is a high level of safety.

\section{Conclusions}

According to the historical accident risk statistics and JSA analysis of the gas plant, the gas turbine of the gas plant is the risk unit of the accident. Human factor, gas turbine, steam turbine, gas system, electrical system, waste heat boiler, environmental factors and management factors are the main risks of gas power plant. And the main influence factors are the defects of equipment, lack of monitoring and people's safety consciousness. An Instance gas power company is chosen to analyze gas accident hazard. The conclusions are shown below.

(1) Through the fuzzy analytic hierarchy process (AHP) programming, the accident risk of the instance gas power company is the highest gas system, mainly because that equipment is sealed and gas detection equipment is not sensitive which causes gas leakage.

(2) By using CASST QRA to analyze the major pipeline leakage accident of the instance gas power company, the dead radius of fire explosion is $55 \mathrm{~m}$, and the damage probability is $1 * 10^{-7}$ on the crowd around the factory outside.

(3) Fuzzy comprehensive assessment and CASST QRA analysis can be used to assess the accident risk of gas power enterprises, and provide effective technical means for gas enterprises to carry out accident risk assessment control.

\section{Acknowledgements}

This paper is supported by general project of China University of Labor Relations (17YY005).

\section{References}

[1] Neil Michison, Georgios A. Papadakis. Safety management systems under Seveso II [J]: Implementation and assessment. Journal of Loss Prevention in the Process Industries. 1999, 12 (1): 43-51.

[2] Sun Yasheng. The application of fuzzy network analysis in the risk assessment of offshore wind projects. [D]. Dalian: Dalian University of Technology, 2008: 2-3.

[3] Lee C. Assessment H., Meliopoulos S., James A. P. Graphical Method for Safety of Winter Meeting Grounding Systems [A]. IEEE Power Engineering Society [C]. 2000: 2016--2021.

[4] Demichela M, Piccinini N, Romano A. Risk analysis as a basis for safety management system [J]. Journal of Loss Prevention in Process Industries, 2004, 17 (3): 179-185.

[5] Zhao Wei. Common risk and control investigation of gas power plant. [J]. Technology wind, 2016.09.: 179-180.

[6] Li Keqin. Power production safety risk identification and application. [J]. Science BBS, 2016.04.081: 93.

[7] Liu Ningning. Safety production alert and control research of power supply company in Harbin. [D]. Jilin University, 2012: 13-28.

[8] Sun Hongxing. Research on risk analysis and control model of power generation enterprise. [D]. North China power university, 2014: 19-61.

[9] Hu Xiang. Risk identification and control of applications in the operation of grid power dispatch. [D]. Sichuan University, 2006: 35-36.

[10] Xie Chuansheng, Zhao Chenchen. Research on Gas Power Generation Risk Assessment Based on Fuzzy Neural Network. [J]. Science and Technology \& Innovation, 2016.32: 2-3.

[11] Li Zhan, Shao Hui, Su Yaochen. Risk- warning Technology of Natural Gas Power Generation Base on Information Diffusion Theory. [J]. Safety and Environmental Engineering, 2016.07.23 (4): 144-147. 